\title{
The Professor Is In
}

\author{
Neil J MacKinnon
}

$\mathrm{L}$ et me start by setting the record straight: Yes, I am a university-based (academic) pharmacist who does not work in a hospital. Of course, as pharmacists, we have all spent time in university, but there can be a wide gulf between the worlds of academia and hospital pharmacy practice. Nonetheless, we have (thankfully) moved past the stereotypical image of the male university professor smoking a pipe and wearing a tweed jacket with elbow patches; you can ask my students whether I'm absent-minded. Now, where was I again? Ah, yes ...

Make no mistake, though: my professional roots lie in hospital pharmacy practice. My most vivid patient care memories are from the University of Wisconsin Hospital and Clinics, where I completed a Master's degree in hospital pharmacy and a residency in hospital pharmacy administration. Even though that was 15 years ago, I can still clearly remember being called down to the emergency department as a member of the pediatrics team when 2 children who had been in an apartment fire were airlifted to the hospital. My 2 mentors as part of that program had both been presidents of the American Society of Hospital Pharmacists (now the American Society of HealthSystem Pharmacists), and they challenged us, as residents, to give back to the profession through our professional associations.

Later, during my PhD studies at the University of Florida, I worked part-time as a pharmacist with a health technology company. About once a month, I would spend 2 or 3 days training pharmacists at their own practice sites on the use of software that linked hospital pharmacy computer systems with laboratory information. Through this experience, I witnessed almost every conceivable type of hospital, from small hospitals in rural Kentucky and Georgia to large academic medical centres in urban settings like Los Angeles.

I returned to Canada just over 10 years ago, and since then I've been blessed to work with many hospital pharmacists from coast to coast. I've had the opportunity to partner with hospital pharmacists in evaluating practice change in areas such as seamless care and medication reconciliation, and I've led many staff retreats and workshops on leadership and career satisfaction. I have found our nation's hospital pharmacists to be inspiring, innovative, and interesting.

One reason that I'm particularly pleased to serve on the presidential track of CSHP at this time is that the key issues facing hospital pharmacy and academia have become closely aligned. For example, the move to the entry-level PharmD has huge implications, such as the required capacity for additional practice experience rotations in hospitals, the salary and job expectations of new graduates, and the impact on existing $\mathrm{BSc}$ (Pharm)-trained pharmacists. Those in academia and hospital pharmacy need to work together to address these challenges, although to be sure, I will be representing the interests of Canadian hospital pharmacists during my term in office.

So, yes, as a new member of the CSHP presidential team, I do bring a slightly different perspective to the table. There is no need to worry, though; you won't see me wearing a tweed jacket with elbow patches anytime soon. A kilt, though, that's another story ...

Neil J MacKinnon, BSc(Pharm), MSc(Pharm), PhD, FCSHP, is President Elect and Vision Liaison of CSHP. 